\section{Proactive promotion}

Jon Turner, John Ravenscroft

\& Lara Isbel
In 1991 the number of female professors of physics in the UK doubled: it went from one to two! By 2009/10, it had risen to 36 - clearly a huge improvement. But that is still 36 out of a total of 650 professors of physics. (Tapping all our Talents, 2012)

The above report was published by the Royal Society of Edinburgh in 2012 but there continues to be a much lower proportion of women in senior academic roles such as senior lecturer, reader and professor compared to the proportion of women in lecturer and postdoctoral researcher posts in most academic disciplines.

One factor which may be influencing the relatively low proportion of women at senior grades is the promotion process. Fewer women than men apply for promotions. Similar to recruitment, when you start with a gender imbalance in the applicant pool it is very difficult to change this without unfairly discriminating against the majority group.

Several schools in the University have made changes to their promotion processes to reduce the pressure on individuals to nominate themselves for promotion. This is not positive discrimination. The aim is to ensure that all those who should be considered for promotion are considered.

There are benefits to organisations in addressing this issue. Taking a more proactive approach to recognising the qualities and skills that individuals could bring to leadership roles can demonstrate that there are many different ways to be a successful leader. This may increase the appeal of senior roles to a wider pool of people (women and men) held back by narrow perceptions or experiences of how senior staff 'should' act or the level of performance required to be promoted to those roles. It can also mean organisations are more likely to reward and recognise talented people who feel uncomfortable or boastful talking about their successes.

Putting systems in place to support people to apply for promotion can turn the experience from something which causes anxiety and frustration into one that is supportive and enabling: this is better for everyone.

\section{Ingredients}

- Annual cycle of academic promotions, and annual reviews and performance development reviews.

- Job descriptions and information on achievement and contribution for all staff.

- Process by which manager and/or head of school or service can identify potential cases for promotion without depending on self-nomination.

- Senior colleagues who can mentor and support people through the promotion process. 


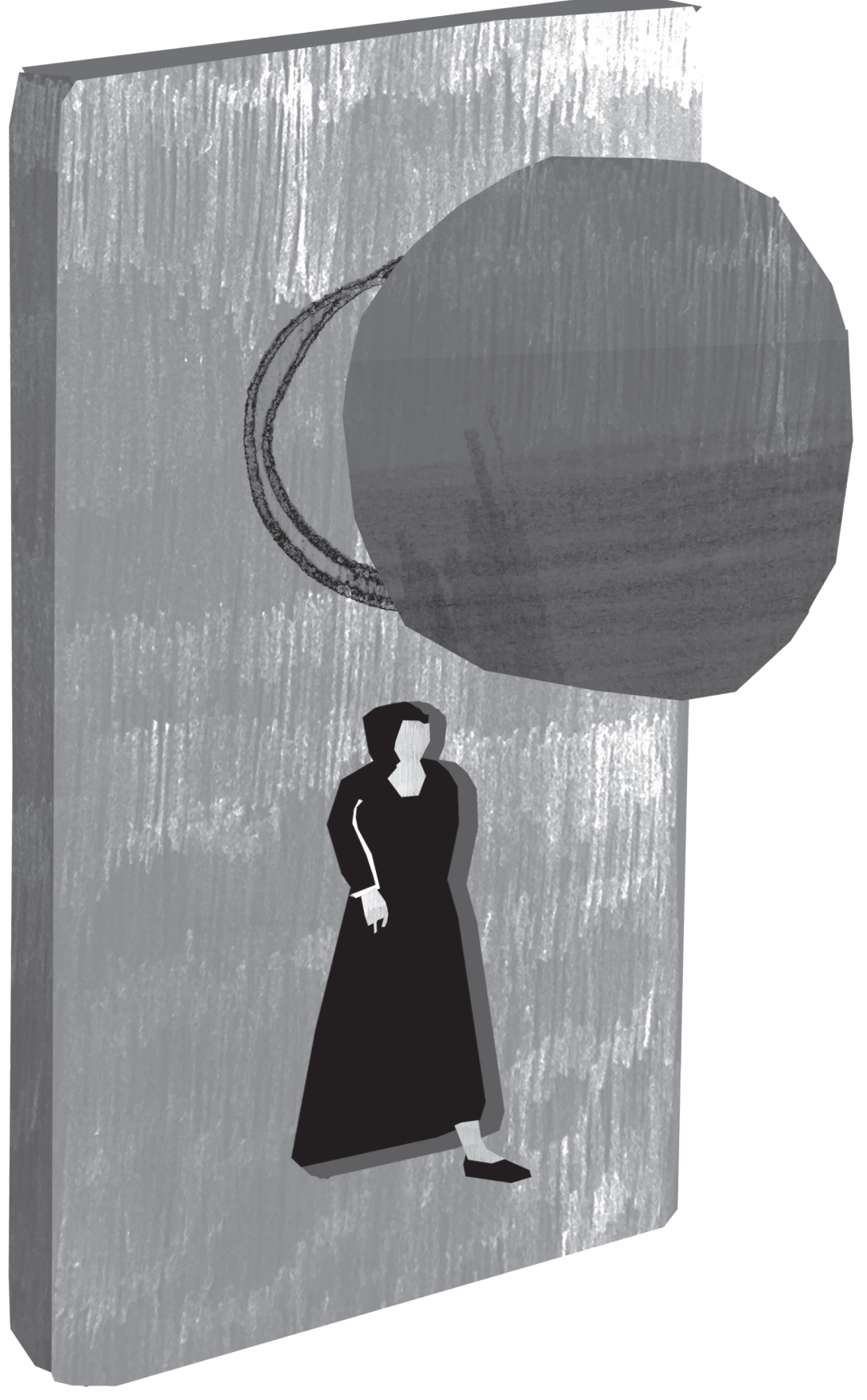




\section{Method}

1. Clearly communicate the level of performance or achievements required for promotion to different grades so staff know what to work towards and prioritise. Academic grade profiles can be a helpful starting point. For academic posts, it is likely people will need evidence of achievement in research, in teaching and in academic citizenship and engagement. Where possible, provide examples of achievements relevant to your discipline. This can provide a useful benchmark and help people to judge their progress. The University's 'Exemplars of Excellence in Student Education' (UoE Exemplars, 2015) and the Teaching Matters website (http:// www.ed.ac.uk/staff/teaching-matters) are useful resources to explore.

2. Discuss promotion and career development as part of everyone's annual review/performance development review. The School of Engineering and the School of Biomedical Sciences introduced this as part of their Athena SWAN action plan. Most university HR (human resource) departments provide guidance and training sessions for reviewers on how to have effective development conversations.
3. Take time to discuss and recognise achievements. Some people are very confident in talking about their achievements; others would rather have their teeth pulled out. As a reviewer, look at the evidence for achievements - and tell people when they are down-playing their experience compared to their peers.

4. Identify senior staff members who can advise on the process. The Moray House School of Education have senior mentors who help and support colleagues to prepare their promotion applications, particularly the job matching forms. Feedback on how to build a narrative around your experience and achievements, and the level of evidence to provide, can be particularly useful.

5. Systematically consider all eligible candidates for promotion in each round. The Roslin Institute and the School of Biomedical Sciences now do this as standard. This reduces the need for people to self-nominate and ensures that all potential candidates are considered to see which meet the criteria for promotion. In these departments, if the case for promotion is confirmed it is submitted through the normal process to college/support group committees.

6. Fair promotion process. Transparency is important. Do you have clear guidelines on what to submit for 
promotion, the criteria used to assess application, how decisions are made and who makes the decision? Is there also guidance on how to appeal a decision or resubmit an application? Providing briefing sessions to staff and nominating experienced people who can answer promotion-related queries can make the process less daunting.

\section{Give constructive feedback. If}

someone has been unsuccessful in the promotion round, providing guidance on specific reasons why with advice on how to address this in future applications is helpful. Being knocked back from promotion can be difficult news. It is harder to move on from with limited feedback.

8. Track who you are promoting. Does the gender balance of the people receiving promotions and additional increments generally reflect the gender balance of your department? How long does it take people to be promoted to different grades? If there are any unexpected trends, these may be worth exploring further.

9. Be mindful of the salary gap. Does your school have a significant disparity in pay for men and women on the same grade with equivalent levels of experience? What steps can you take to rectify this?

\section{Cooks tips}

Not everyone wants to be promoted. This is fine. It is important that there is an equal opportunity to apply and that the process is fair and transparent, but individuals shouldn't feel pressured into progressing to more senior roles. We fully acknowledge that you can have a successful and rewarding career at any grade.

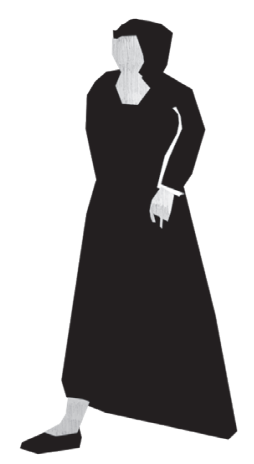

Proactive promotion 